\title{
Níveis de inulina em rações de origem animal e vegetal para frangos de corte
}

\author{
Inulin levels on animal and vegetal diets for broiler chicken
}

\author{
Wagner Tiago Mozer da Silva ${ }^{1}$; Ricardo Vianna Nunes²; Carina Scherer ${ }^{3 *}$; \\ Paulo Cesar Pozza ${ }^{2}$; Magali Soares dos Santos Pozza²; Matias Djalma Appelt ${ }^{1}$; \\ Cinthia Eyng ${ }^{1}$
}

\begin{abstract}
Resumo
Objetivou-se avaliar o efeito dos níveis de inclusão de inulina em rações formuladas com ingredientes de origem vegetal e animal, sobre o desempenho e o rendimento de carcaça de frangos de corte. Foram utilizados 1056 pintos de um dia de idade, alojados em cama reutilizada, distribuídos em um delineamento inteiramente casualizado, em esquema fatorial 2 x 4 (dietas vegetal e animal x níveis de inclusão de inulina), totalizando oito tratamentos, seis repetições e 22 aves por unidade experimental. Os níveis de inulina testados foram: $0 ; 0,25 ; 0,50$ e $0,75 \%$. Aos sete, 21 e 40 dias de idade foram avaliados: peso final, ganho de peso, consumo de ração, conversão alimentar e viabilidade. Aos 40 dias foram avaliados: índice de eficiência produtiva, variáveis econômicas e rendimento de carcaça. Não foram observados efeitos dos níveis de inulina e tipo de dieta sobre o desempenho de um a sete dias de idade $(\mathrm{P}>0,05)$. De um a 21 dias o consumo de ração reduziu $(\mathrm{P}<0,05)$ com a inclusão de inulina. A ração formulada com ingredientes de origem animal proporcionou maior rendimento de carcaça e de coxa $(\mathrm{P}<0,05)$ aos 40 dias de idade. A gordura abdominal reduziu $(\mathrm{P}<0,05)$ conforme aumentou o nível de inclusão de inulina nas dietas. Conclui-se que a inulina pode ser utilizada, até o nível de $0,75 \%$ em rações de origem animal ou vegetal sem prejudicar o desempenho.
\end{abstract}

Palavras-chave: Bifidobacterium bifidum, Lactobacillus acidophilus, prebiótico, desempenho, rendimento de carcaça

\begin{abstract}
This study aimed to evaluate the effect of inulin inclusion levels in diets with ingredients of vegetable and animal origin, on the performance and carcass yield of broilers chickens. Were used 1056 chicks, of one day old, housed in reused poultry litter, distributed in a completely randomized design, in a factorial $2 \times 4$ (animal and vegetable diets $\mathrm{x}$ inclusion levels of inulin), totaling eight treatments, six replicates and 22 birds per experimental unit. The inulin levels were: $0,0.25,0.50$ and $0.75 \%$. At seven, 21 and 40 days of age were evaluated: final weight, weight gain, feed intake, feed conversion and viability. At 40 days were evaluated: productive efficiency, economic variables and carcass yield. No effects of inulin and type of diet were observed on the performance from one to seven days old $(\mathrm{P}>0.05)$. From one to 21 days, a feed consumption decreased $(\mathrm{P}<0.05)$ with the inclusion of inulin. The diet with animal
\end{abstract}

\footnotetext{
${ }^{1}$ Discentes de Mestrado no Programa de Pós Graduação Stricto Sensu em Zootecnia da Universidade Estadual do Oeste do Paraná, UNIOESTE, Marechal Cândido Rondon, PR. E-mail: wtmozer@gmail.com; matias.appelt@gmail.com; cinthiaeyng@hotmail.com

${ }^{2}$ Profs. do Programa de Pós-graduação Stricto Sensu em Zootecnia, UNIOESTE, Marechal Cândido Rondon, PR. E-mail: nunesrv@hotmail.com; pcpozza@yahoo.com.br; magaspozza@hotmail.com

${ }^{3}$ Bolsista do Programa Nacional de Pós-Doutorado no Programa de Pós Graduação Stricto Sensu em Zootecnia, UNIOESTE, Marechal Cândido Rondon, PR. E-mail: carina_scherer@hotmail.com

* Autor para correspondência
} 
ingredients provided greater carcass yield, thigh and lower abdominal fat percentage $(\mathrm{P}<0.05)$ at 40 days of age. The abdominal fat reduced $(\mathrm{P}<0.05)$ with the inclusion of inulin incresase. It is concluded that inulin can be used, up to the level of $0.75 \%$ in diets of animal or vegetable origin without sacrificing the broilers performance.

Key words: Bifidobacterium bifidum, carcass yield, inulin, Lactobacillus acidophilus, performance, prebiotic

\section{Introdução}

Os primeiros aditivos utilizados na avicultura foram os antibióticos promotores de crescimento, que tinham por finalidade prevenir o aparecimento de doenças, além de melhorar a eficiência produtiva dos animais. Todavia, a partir da década de 80 , a segurança dos antibióticos começou a ser questionada, principalmente devido ao seu uso rotineiro na alimentação das aves (BRUMANO; GATTAS, 2009).

De acordo com Palermo (2006), na União Européia, até dezembro de 2005, ainda eram liberados alguns antibióticos como a flavomicina, avilamicina, salinomicina e monensina sódica, porém, atualmente os antimicrobianos estão proibidos para uso como aditivo alimentar.

A microbiota do trato gastrintestinal é dependente da dieta como principal fonte de substrato para o seu crescimento e metabolismo. Dessa forma, o uso de prebiótico ou simbióticos em rações para aves pode promover condições para uma microbiota benéfica e estável, auxiliando na digestão do alimento, absorção de nutrientes e inibindo a proliferação de microrganismos patogênicos, proporcionando melhor desempenho e saúde para os animais (STEFE; ALVES; RIBEIRO, 2008).

O termo prebiótico é utilizado para designar ingredientes alimentares não digeríveis que beneficiam o hospedeiro por estimular seletivamente o crescimento e/ou a atividade de uma ou um número limitado de espécies bacterianas no cólon (GIBSON; ROBERFROID, 1995). Uma variedade de microrganismos tem sido utilizada como probióticos, incluindo espécies pertencentes aos gêneros Bacillus, Bifidobacterium, Enterococcus, Lactobacillus, Lactococcus, Streptococcus, e algumas espécies de leveduras, como as do gênero Saccharomyces. As espécies do gênero Lactobacillus e Bifidobacterium têm mostrado um grande potencial como probiótico, tanto na alimentação humana quanto na nutrição animal, gerando efeitos benéficos para o hospedeiro (COLLINS; GIBSON, 1999).

Dentre os prebióticos utilizados na alimentação de animais, encontramos a inulina, que consiste em um carboidrato largamente encontrado na natureza, funcionando como carboidrato de reserva em muitas plantas. A inulina é uma frutana polidispersa, constituída de uma mistura de polímeros e oligômeros superiores lineares de frutose. As principais fontes de inulina são o alho, a cebola e aspargo, que possuem entre 0,3 a $6 \%$ do peso fresco, entretanto, para alcachofra de Jerusalém, chicória, dália e yacon as concentrações de inulina e oligofrutoses podem chegar até $20 \%$ do peso fresco, fazendo destes vegetais importantes fontes destas substâncias (HAULY; MOSCATTO, 2002).

A ingestão de inulina tem como resultado um aumento significativo da Bifidobacteria benéfica no intestino, e, ao mesmo tempo, a presença de bactérias indesejáveis é reduzida significativamente. Este prebiótico também tem um impacto positivo na absorção de minerais como cálcio, fósforo e magnésio (ROBERFROID, 2007).

Neste contexto, objetivou-se avaliar o efeito dos níveis de inclusão de inulina em rações formuladas com ingredientes de origem vegetal e animal, sobre o desempenho e rendimento de carcaça de frangos de corte. 


\section{Material e Métodos}

O experimento foi realizado no Aviário Experimental, localizado na Estação Experimental Antônio Carlos dos Santos Pessoa pertencente à Universidade Estadual do Oeste do Paraná - UNIOESTE, Campus de Marechal Cândido Rondon - PR durante os meses de agosto de 2009 a setembro de 2009.

Foram utilizados 1056 pintos de frango de corte de um dia, machos, da linhagem Cobb 500, com peso médio inicial de 47,86 g, vacinados no incubatório contra Marek, Bouba Aviária, Bronquite Infecciosa e Gumboro. O delineamento experimental foi inteiramente casualizado, em esquema fatorial 2 x 4 (dietas vegetal e animal x níveis de inclusão de inulina) totalizando oito tratamentos, com seis repetições cada, utilizando 22 aves por unidade experimental. Os níveis de inclusão de inulina $(0,00 ; 0,25 ; 0,50 ; 0,75 \%)$.

Foram utilizadas três fases experimentais: pré-inicial (1 a 7 dias de idade), inicial (8 a 21 dias de idade) e crescimento (22 a 40 dias de idade), para as quais foram formuladas rações de acordo com as exigências nutricionais propostas por Rostagno et al. (2005) (Tabela 1). Todas as rações continham probiótico, composto por uma mistura de Lactobacillus acidophillus (3,5 x $10^{11}$ UFC); Enterococcus faecium (3,5 x $\left.10^{11} \mathrm{UFC}\right)$ e Bifidobacterium bifidum (3,5 x $10^{11}$ UFC) por $1000 \mathrm{~g}$ de produto. A utilização do probiótico foi realizada seguindo as especificações do fabricante (um quilo por tonelada para o período de 1 a 21 dias de idade e 500 gramas por tonelada de 22 a 42 dias de idade). A inclusão da inulina foi realizada em substituição ao material inerte da ração.

As aves foram alojadas em cama reutilizada composta de maravalha de pinus, sendo esta a segunda utilização da mesma, tomando-se o cuidado de recobrir a cama usada com $1 \mathrm{~cm}$ maravalha nova. Durante todo o experimento as aves receberam água e ração ad libitum e diariamente foi registrada a umidade relativa do ar e a temperatura interna do galpão com termohigrômetro digital. As médias de temperaturas máximas e mínimas, como também, a umidade, foram monitoradas e registradas diariamente no galpão, pela manhã e à tarde, durante toda a fase experimental. Durante os primeiros dias de idade as aves receberam aquecimento artificial, quando necessário. O programa de iluminação foi de 24 horas de luz (natural e artificial). 
Tabela 1. Composição percentual e calculada das rações experimentais em suas respectivas fases.

\begin{tabular}{|c|c|c|c|c|c|c|}
\hline \multirow{3}{*}{ Ingredientes } & \multicolumn{6}{|l|}{ Fases } \\
\hline & \multicolumn{2}{|c|}{ Pré-Inicial } & \multicolumn{2}{|l|}{ Inicial } & \multicolumn{2}{|c|}{ Crescimento } \\
\hline & Vegetal & Animal & Vegetal & Animal & Vegetal & Animal \\
\hline Milho & 51,03 & 52,73 & 53,55 & 56,77 & 56,49 & 61,31 \\
\hline Farelo de soja (45\%) & 38,97 & 35,84 & 35,98 & 30,94 & 32,40 & 24,85 \\
\hline Óleo de soja & 3,91 & 3,18 & 4,85 & 3,72 & 5,79 & 4,10 \\
\hline Farinha de carne e osso & 0,00 & 1,50 & 0,00 & 2,00 & 0,00 & 3,00 \\
\hline Farinha de vísceras de aves & 0,00 & 1,50 & 0,00 & 2,00 & 0,00 & 3,00 \\
\hline Fosfato bicálcico & 1,95 & 1,20 & 1,85 & 0,86 & 1,70 & 0,22 \\
\hline Calcário calcítico & 0,93 & 0,87 & 0,90 & 0,82 & 0,85 & 0,74 \\
\hline Sal comum & 0,52 & 0,48 & 0,50 & 0,45 & 0,48 & 0,40 \\
\hline $\mathrm{DL}$ - metionina & 0,37 & 0,37 & 0,27 & 0,27 & 0,25 & 0,25 \\
\hline $\mathrm{L}-$ lisina $\mathrm{HCl}$ & 0,34 & 0,35 & 0,20 & 0,25 & 0,20 & 0,27 \\
\hline $\mathrm{L}$ - treonina & 0,15 & 0,15 & 0,07 & 0,09 & 0,06 & 0,08 \\
\hline Antioxidante $^{1}$ & 0,02 & 0,02 & 0,02 & 0,02 & 0,02 & 0,02 \\
\hline Suplemento mineral ${ }^{2}$ & 0,05 & 0,05 & 0,05 & 0,05 & 0,05 & 0,05 \\
\hline Suplemento vitamínico ${ }^{3}$ & 0,10 & 0,10 & 0,10 & 0,10 & 0,10 & 0,10 \\
\hline Cloreto de colina $60 \%$ & 0,06 & 0,06 & 0,06 & 0,06 & 0,06 & 0,06 \\
\hline Probiótico $^{4}$ & 0,10 & 0,10 & 0,10 & 0,10 & 0,05 & 0,05 \\
\hline Inerte $^{5}$ & 1,50 & 1,50 & 1,50 & 1,50 & 1,50 & 1,50 \\
\hline Total & 100,00 & 100,00 & 100,00 & 100,00 & 100,00 & 100,00 \\
\hline \multicolumn{7}{|l|}{ Composição calculada } \\
\hline Energia Met. (kcal/kg) & 2,950 & 2,950 & 3,050 & 3,050 & 3.150 & 3,150 \\
\hline Proteína bruta (\%) & 22,53 & 22,74 & 21,14 & 21,14 & 19,73 & 19,73 \\
\hline Cálcio (\%) & 0,942 & 0,942 & 0,899 & 0,899 & 0,837 & 0,837 \\
\hline Fósforo disponível (\%) & 0,471 & 0,471 & 0,449 & 0,449 & 0,418 & 0,418 \\
\hline Lisina digestível (\%) & 1,363 & 1,363 & 1,189 & 1,189 & 1,099 & 1,099 \\
\hline Metionina digestível (\%) & 0,675 & 0,676 & 0,562 & 0,566 & 0,523 & 0,529 \\
\hline Met. + Cist. digestível (\%) & 0,968 & 0,968 & 0,920 & 0,925 & 0,791 & 0,791 \\
\hline Triptofano digestível (\%) & 0,249 & 0,241 & 0,234 & 0,219 & 0,215 & 0,194 \\
\hline Treonina digestível (\%) & 0,886 & 0,886 & 0,773 & 0,773 & 0,714 & 0,714 \\
\hline Potássio (\%) & 0,856 & 0,822 & 0,808 & 0,750 & 0,751 & 0,663 \\
\hline Sódio (\%) & 0,224 & 0,224 & 0,218 & 0,218 & 0,208 & 0,208 \\
\hline
\end{tabular}

${ }^{1}$ BHT (Hidroxi Butil Tolueno); ${ }^{2}$ Suplemento mineral, conteúdo: Mg - 16,0 g; Fe - 100,00 g; Zn - 100,0 g; Cu - 2,0 g; Co - 2,0 g; I2,0 g; e Veículo q. s. p. - 1.000 g; ${ }^{3}$ Suplemento vitamínico, conteúdo: vit. A - 10.000.000 UI; vit. D3 - 2.000.000 UI; vit. E - 30.000 UI; vit. B1 - 2,0 g; vit. B6 - 4,0 g; Ac. Pantotênico- 12,0 g; Biotina- 0,10 g; vit. K3 - 3,0 g; Ac. fólico - 1,0 g; Ac. Nicotínico- 50,0 g; vit. B12 - $15.000 \mathrm{mcg}$; Selênio- 0,25 g; e Veículo q. s. p. - 1.000 g. ${ }^{4}$ composto por uma mistura de Lactobacillus acidophillus

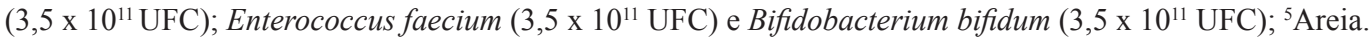

Fonte: Elaboração dos autores.

Aos 7, 21 e 40 dias de idade todas as aves foram pesadas, bem como o consumo de ração quantificado. As variáveis avaliadas foram: peso final $(\mathrm{P})$, ganho de peso (GP), consumo de ração (CR), conversão alimentar (CA) e viabilidade (VB). Ao final do período experimental, avaliou-se o Índice de Eficiência Produtiva (IEP), utilizando-se a seguinte fórmula:

\section{$\mathrm{IEP}=[($ GMD $\times$ Viabilidade $) /($ IA $\times$ CA $)] \times 100$}

Em que, GMD corresponde ao ganho de peso médio diário do lote $(\mathrm{kg})$, viabilidade é o percentual de frangos vivos no final do período experimental, IA, equivale à idade do abate (dias) e CA corresponde à conversão alimentar. 
Aos 40 dias de idade, as aves foram submetidas a um jejum de 6 horas, quando então, duas aves de cada unidade experimental, representando o peso médio de cada parcela $( \pm 10 \%)$, foram abatidas por meio de deslocamento cervical, com posterior sangria, escaldagem, retirada de penas e evisceração. As carcaças foram pesadas em balança digital para avaliação do rendimento de carcaça, em relação ao peso vivo da ave no abate. Posteriormente realizouse o corte das partes nobres (peito, coxa, sobrecoxa e asa), os quais foram pesados para calcular o rendimento dos cortes, em função do peso da carcaça eviscerada. Também foi pesada a gordura abdominal e em seguida determinado a porcentagem de gordura abdominal em relação ao peso da ave ao abate. Considerou-se gordura abdominal aquela depositada na região abdominal, próxima a Bursa de Fabricius e a moela.

Para verificar a viabilidade econômica da utilização de prebiótico nas rações foi determinado custo médio da ração por quilograma de peso vivo ganho (BELLAVER et al., 1985), conforme segue:

$$
\mathrm{CMr}=(\mathrm{Q} \times \mathrm{P}) / \mathrm{G}
$$

Onde, $\mathrm{CMr}$ equivale ao custo médio da ração/kg de peso vivo ganho pelas das aves por tratamento, Q é a quantidade de ração consumida no tratamento (g), P é o preço da ração $(\mathrm{R} \$ / \mathrm{kg})$ na época de realização do experimento, e $\mathrm{G}$ corresponde ao ganho de peso ( $\mathrm{g}$ ) das aves por tratamento no período experimental.
Em seguida foi calculado o índice de eficiência econômica (IEE) e índice de custo (IC), proposto por Barbosa et al. (1992) para avaliar o impacto financeiro dos tratamentos, em relação ao tipo de ração e prebiótico utilizados, da seguinte forma:

$$
\begin{aligned}
& \mathrm{IEE}=(\mathrm{MCMr} \times 100) / \mathrm{CMr} \\
& \mathrm{IC}=(\mathrm{CMr} \times 100) / \mathrm{MCMr}
\end{aligned}
$$

Em que, MCMr corresponde ao menor custo médio da ração entre os tratamentos e CMr equivale ao custo médio da ração.

Os efeitos do tipo de ração, níveis de inulina e da interação entre ambos foram verificados pela análise de variância. A comparação entre médias de tipo de ração foi feita utilizando-se o teste $\mathrm{F}$. O efeito dos níveis de inulina sobre as características avaliadas foi avaliado por meio de regressão polinomial. O nível de significância de 0,05 foi adotado em todas as análises, que foram realizadas utilizando o Sistema de Análise Estatística e Genética - SAEG (1999) (verão 8.0).

\section{Resultados e Discussão}

Não foram observadas interações significativas $(\mathrm{P}>0,05)$ entre os níveis de inclusão de inulina e o tipo de ingredientes utilizados na ração para as variáveis de desempenho de um a sete dias de idade (Tabela 2). Isoladamente, o tipo de dieta e a inclusão da inulina também não exerceram efeito sobre as variáveis de desempenho durante a fase inicial. 
Tabela 2. Desempenho de frangos de corte de 1 a 7 dias de idade alimentados com dietas contendo ingredientes de origem vegetal ou animal e níveis crescentes de inulina.

\begin{tabular}{|c|c|c|c|c|c|c|c|c|c|c|}
\hline & Ração & $0,00 \%$ & $0,25 \%$ & $0,50 \%$ & $0,75 \%$ & Média & Inulina & Ração & IxR & CV\% \\
\hline \multirow{3}{*}{$\begin{array}{l}\text { Consumo de Ração } \\
\text { (g) }\end{array}$} & Vegetal & 143,48 & 142,59 & 141,37 & 142,61 & 142,51 & \multirow{3}{*}{ ns } & \multirow{3}{*}{$s$} & \multirow{3}{*}{ ns } & \multirow{3}{*}{4,70} \\
\hline & Animal & 137,49 & 142,43 & 143,30 & 144,03 & 141,81 & & & & \\
\hline & Média & 140,48 & 142,51 & 142,34 & 143,32 & & & & & \\
\hline \multirow{3}{*}{$\begin{array}{l}\text { Ganho de Peso } \\
\text { (g) }\end{array}$} & Vegetal & 129,08 & 128,71 & 127,73 & 127,63 & 128,29 & \multirow{3}{*}{ ns } & \multirow{3}{*}{ ns } & \multirow{3}{*}{ ns } & \multirow{3}{*}{5,12} \\
\hline & Animal & 122,53 & 126,86 & 129,97 & 128,95 & 127,08 & & & & \\
\hline & Média & 125,81 & 127,79 & 128,85 & 128,29 & & & & & \\
\hline \multirow{3}{*}{$\begin{array}{l}\text { Conversão Alimentar } \\
(\mathrm{g} / \mathrm{g})\end{array}$} & Vegetal & 1,112 & 1,110 & 1,107 & 1,118 & 1,112 & \multirow{3}{*}{ - } & \multirow{3}{*}{ ns } & \multirow{3}{*}{ ns } & \multirow{3}{*}{3,48} \\
\hline & Animal & 1,123 & 1,123 & 1,103 & 1,118 & 1,117 & & & & \\
\hline & Média & 1,117 & 1,117 & 1,105 & 1,118 & & & & & \\
\hline
\end{tabular}

ns - não significativo; CV - coeficiente de variação.

Fonte: Elaboração dos autores.

Resultados semelhantes foram verificados por Fukata et al. (1999), que relataram que a utilização de frutoligossacarídeos (FOS) na ração para frangos, aos sete dias de idade, não modificaram o desempenho das aves, atribuindo o resultado ao ambiente, nível de estresse, concentrações de microrganismos e baixo desafio sanitário que os aves foram submetidas.

Contrariando os resultados deste trabalho, Santos, Russo e Maiorka (2009), trabalhando com antibióticos, mananoligossacarídeos (MOS), óleo essencial e a combinação de MOS com ácido orgânico, verificaram melhora na conversão alimentar com a utilização dos diferentes aditivos quando comparado com o tratamento controle negativo, isento de aditivos, com frangos de corte aos 7 dias de idade.

Os resultados observados no presente trabalho, onde não houve efeito do uso da inulina sobre o desempenho das aves, podem ser explicados pelo baixo desafio a que as aves foram submetidas, já que a cama foi utilizada em apenas um lote anterior. Além disso, todas as rações continham probiótico, como promotor de crescimento, com a finalidade de avaliar o efeito de simbiose entre os dois produtos (probiótico + prebiótico), demonstrando que a adição da inulina sobre o probiótico utilizado não apresentou diferenças nos resultados de desempenho dos frangos de corte.

Não houve interação $(\mathrm{P}>0,05)$ entre os níveis de inclusão de inulina e o tipo de ração utilizada (produtos de origem vegetal ou animal) sobre o desempenho das aves, no período de um a 21 dias de idade (Tabela 3). Entretanto, neste período, o consumo de ração reduziu linearmente $(\mathrm{P}<0,05)$ com o aumento da inclusão de inulina $(\mathrm{CR}=$ 1,18281 - 0,0365861 X; $\left.\mathrm{R}^{2}=0,68\right)$. 
Tabela 3. Desempenho de frangos de corte de 1 a 21 dias de idade alimentados com dietas contendo ingredientes de origem vegetal ou animal e níveis crescentes de inulina.

\begin{tabular}{|c|c|c|c|c|c|c|c|c|c|c|}
\hline & Ração & $0,00 \%$ & $0,25 \%$ & $0,50 \%$ & $0,75 \%$ & Média & Inulina & Ração & IxR & $\mathrm{CV} \%$ \\
\hline \multirow{3}{*}{$\begin{array}{l}\text { Consumo de } \\
\text { Ração (g) }\end{array}$} & Vegetal & 1184,75 & 1156,12 & 1176,55 & 1150,42 & 1166,96 & \multirow{3}{*}{$0,0282^{*}$} & \multirow{3}{*}{ ns } & \multirow{3}{*}{ ns } & \multirow{3}{*}{2,32} \\
\hline & Animal & 1183,20 & 1176,78 & 1174,29 & 1150,58 & 1171,21 & & & & \\
\hline & Média & 1183,98 & 1166,45 & 1175,42 & 1150,50 & & & & & \\
\hline \multirow{3}{*}{$\begin{array}{l}\text { Ganho de } \\
\text { Peso (g) }\end{array}$} & Vegetal & 922,39 & 917,58 & 896,51 & 896,78 & 908,31 & \multirow{3}{*}{ ns } & \multirow{3}{*}{ ns } & \multirow{3}{*}{ ns } & \multirow{3}{*}{3,07} \\
\hline & Animal & 926,27 & 917,50 & 926,60 & 915,89 & 921,57 & & & & \\
\hline & Média & 924,33 & 917,54 & 911,55 & 906,33 & & & & & \\
\hline \multirow{3}{*}{$\begin{array}{l}\text { Conversão } \\
\text { Alimentar } \\
(\mathrm{g} / \mathrm{g})\end{array}$} & Vegetal & 1,285 & 1,262 & 1,313 & 1,283 & 1,286 & \multirow{3}{*}{ ns } & \multirow{3}{*}{ ns } & \multirow{3}{*}{ ns } & \multirow{3}{*}{3,31} \\
\hline & Animal & 1,278 & 1,284 & 1,269 & 1,257 & 1,272 & & & & \\
\hline & Média & 1,281 & 1,273 & 1,291 & 1,270 & & & & & \\
\hline \multirow{3}{*}{$\begin{array}{l}\text { Viabilidade } \\
(\%)\end{array}$} & Vegetal & 99,242 & 96,212 & 98,485 & 98,485 & 98,106 & \multirow{3}{*}{. } & \multirow{3}{*}{ ns } & \multirow{3}{*}{ ns } & \multirow{3}{*}{3,26} \\
\hline & Animal & 96,970 & 100,000 & 99,242 & 96,970 & 98,295 & & & & \\
\hline & Média & 98,106 & 98,106 & 98,864 & 97,727 & & & & & \\
\hline
\end{tabular}

*Efeito linear dos níveis de inulina ( $\left.C R=1,18281-0,0365861 \mathrm{X} ; \mathrm{R}^{2}=0,68\right)$; ${ }^{\text {ns }}$ - não significativo; $\mathrm{CV}$ - coeficiente de variação; Fonte: Elaboração dos autores.

Estes resultados discordam dos encontrados por Godoi et al. (2008), onde as aves alimentadas com prebióticos tiveram um ganho de peso superior às aves que consumiram rações sem aditivos. Silva et al. (2011) também observaram que aves alimentadas com probiótico, prebiótico (inulina) e simbiótico, apresentaram maior peso aos 21 dias de idade e maior ganho de peso, comparado com as aves que receberam rações suplementadas com antibióticos. De modo semelhante, para Junqueira et al. (2006) a utilização de prebiótico proporcionou melhores resultados no peso médio final e ganho de peso aos 21 dias de idade quando comparado com aves que não receberam esta suplementação.

Não houve interação $(\mathrm{P}>0,05)$ entre os níveis de inclusão de inulina e o tipo de ração utilizada sobre as variáveis de desempenho, no período de 1 a 40 dias de idade (Tabela 4). Da mesma forma, independente do tipo de ração e dos diferentes níveis de inclusão de prebiótico, não foi observada diferença $(\mathrm{P}>0,05)$ sobre o peso final, ganho de peso, consumo de ração e conversão alimentar das aves no mesmo período. Confirmando os resultados obtidos por Silva et al. (2011), onde os promotores de crescimento não apresentaram efeitos sobre as variáveis de desempenho.

Estes resultados são semelhantes aos encontrados por Dionizio et al. (2002), que, trabalhando com quatro prebióticos, à base de frutoligossacarídeos (FOS), verificaram que os prebióticos não interferiram no consumo de ração, no ganho de peso e na conversão alimentar em frangos aos 42 dias de idade. Discordando de Xu et al. (2003), que observaram que a inclusão de 4,0 g/kg de FOS na dieta basal aumentou significativamente o ganho médio diário de frangos de corte de 1 a 49 dias. 
Tabela 4. Desempenho de frangos de corte de 1 a 40 dias de idade alimentados com dietas contendo ingredientes de origem vegetal ou animal e níveis crescentes de inulina.

\begin{tabular}{|c|c|c|c|c|c|c|c|c|c|c|}
\hline & Ração & $0,00 \%$ & $0,25 \%$ & $0,50 \%$ & $0,75 \%$ & Média & Inulina & Ração & IxR & $\mathrm{CV} \%$ \\
\hline \multirow{3}{*}{$\begin{array}{l}\text { Consumo de } \\
\text { Ração (g) }\end{array}$} & Vegetal & 4135,18 & 3998,38 & 4135,54 & 4062,86 & 4082,99 & \multirow{3}{*}{ ns } & \multirow{3}{*}{ ns } & \multirow{3}{*}{ ns } & \multirow{3}{*}{2,97} \\
\hline & Animal & 4132,76 & 4074,75 & 4129,32 & 4080,64 & 4104,37 & & & & \\
\hline & Média & 4133,97 & 4036,56 & 4132,43 & 4071,75 & & & & & \\
\hline \multirow{3}{*}{$\begin{array}{l}\text { Ganho de } \\
\text { Peso (g) }\end{array}$} & Vegetal & 2605,22 & 2620,25 & 2550,91 & 2556,24 & 2583,15 & \multirow{3}{*}{ ns } & \multirow{3}{*}{ ns } & \multirow{3}{*}{ ns } & \multirow{3}{*}{3,01} \\
\hline & Animal & 2582,42 & 2569,81 & 2570,85 & 2605,19 & 2582,07 & & & & \\
\hline & Média & 2593,82 & 2595,03 & 2560,88 & 2580,72 & & & & & \\
\hline Conversão & Vegetal & 1,587 & 1,526 & 1,622 & 1,590 & 1,581 & \multirow{3}{*}{ ns } & \multirow{3}{*}{ ns } & \multirow{3}{*}{ ns } & \multirow{3}{*}{2,73} \\
\hline \multirow{2}{*}{$\begin{array}{l}\text { Alimentar } \\
(\mathrm{g} / \mathrm{g})\end{array}$} & Animal & 1,601 & 1,586 & 1,608 & 1,567 & 1,590 & & & & \\
\hline & Média & 1,594 & 1,556 & 1,615 & 1,578 & & & & & \\
\hline \multirow{3}{*}{$\begin{array}{l}\text { Viabilidade } \\
(\%)\end{array}$} & Vegetal & 97,727 & 93,182 & 94,697 & 96,212 & 95,455 & \multirow{3}{*}{ ns } & \multirow{3}{*}{ ns } & \multirow{3}{*}{ ns } & \multirow{3}{*}{4,45} \\
\hline & Animal & 95,455 & 97,727 & 96,970 & 93,182 & 95,833 & & & & \\
\hline & Média & 96,591 & 95,455 & 95,833 & 94,697 & & & & & \\
\hline \multirow{3}{*}{ IEP } & Vegetal & 400,92 & 399,63 & 372,58 & 386,58 & 389,93 & \multirow{3}{*}{ 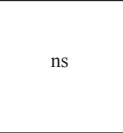 } & \multirow{3}{*}{ ns } & \multirow{3}{*}{ ns } & \multirow{3}{*}{5,38} \\
\hline & Animal & 385,33 & 395,89 & 388,30 & 387,63 & 389,29 & & & & \\
\hline & Média & 393,12 & 397,76 & 380,44 & 387,11 & & & & & \\
\hline
\end{tabular}

ns - não significativo; CV - coeficiente de variação; IEP - índice de eficiência produtiva.

Fonte: Elaboração dos autores.

Albino et al. (2006) estudando o uso de mananoligossacarídeos, encontraram efeitos benéficos no ganho de peso e no peso final de frangos de corte, no período de 1 a 42 dias de idade. Resultados semelhantes foram relatados por Rostagno et al. (2003), que, avaliando o efeito de prebiótico à base de MOS em rações, verificaram melhora no ganho de peso e na conversão alimentar. Entretanto, Flemming et al. (2004), observaram que o ganho de peso diário diminuiu ao utilizar $0,05 \%$ de mananoligossacarídeos em dietas para frangos, em relação ao tratamento controle.

O tipo de ração e os níveis de inclusão de inulina, bem como a interação entre ambos, não influenciaram $(\mathrm{P}>0,05)$ a viabilidade e o índice de eficiência produtiva das aves no período de 1 a 40 dias de idade (Tabela 4). Santos et al. (2005) também não encontraram diferença significativa para viabilidade, em função dos diferentes aditivos promotores de crescimento utilizados. Do mesmo modo, Maia et al. (2009) verificaram que a suplementação de prebiótico à base de mananoligossacarídeos e de $\beta$-glucanos não apresentou efeito sobre a viabilidade, entretanto, aumentou o índice de eficiência produtiva quando comparado com as aves alimentadas com dietas sem promotor de crescimento. Observa-se então que o uso da inulina, como promotor de crescimento, é equivalente ao uso de probióticos e de antibióticos, já que seu efeito não é prejudicial ao desempenho de frangos de corte.

A ração formulada com ingredientes de origem animal proporcionou maior rendimento de carcaça $\mathrm{e}$ de coxa $(\mathrm{P}<0,05)$ aos frangos abatidos com 40 dias de idade, comparada à ração com alimentos de origem vegetal (Tabela 5). Além disso, houve interação entre o tipo de ração e os níveis de inulina $(\mathrm{P}<0,05)$ sobre o rendimento de peito, sendo que, com baixos níveis de inclusão de inulina o rendimento de peito foi maior nas aves que receberam ração contendo ingredientes de origem vegetal, entretanto, à medida que o nível de inclusão de inulina aumentou, a ração contendo ingredientes de origem animal resultou em maior rendimento de peito. 
Tabela 5. Rendimento de carcaça, peito e coxa de frangos de corte abatidos aos 40 dias de idade, alimentados com dietas contendo ingredientes de origem vegetal ou animal e níveis crescentes de inulina.

\begin{tabular}{|c|c|c|c|c|c|c|c|c|c|c|}
\hline & Ração & $0,00 \%$ & $0,25 \%$ & $0,50 \%$ & $0,75 \%$ & Média & Inulina & Ração & IxR & $\mathrm{CV} \%$ \\
\hline \multirow{3}{*}{ Carcaça (\%) } & Vegetal & 73,78 & 73,93 & 73,28 & 73,94 & $73,73 b$ & \multirow{3}{*}{ ns } & \multirow{3}{*}{0,0042} & \multirow{3}{*}{ ns } & \multirow{3}{*}{1,79} \\
\hline & Animal & 73,85 & 74,37 & 74,77 & 75,66 & $74,66 \mathrm{a}$ & & & & \\
\hline & Média & 73,81 & 74,15 & 74,02 & 74,80 & & & & & \\
\hline \multirow{3}{*}{ Peito (\%) } & Vegetal & $36,92 a$ & $36,19 a$ & $36,32 a$ & $34,30 \mathrm{~b}$ & 35,93 & \multirow{3}{*}{ ns } & \multirow{3}{*}{ ns } & \multirow{3}{*}{$0,0066^{*}$} & \multirow{3}{*}{4,12} \\
\hline & Animal & $35,80 \mathrm{~b}$ & $35,11 \mathrm{~b}$ & $36,16 \mathrm{~b}$ & $36,32 \mathrm{a}$ & 35,85 & & & & \\
\hline & Média & 36,36 & 35,65 & 36,24 & 35,31 & & & & & \\
\hline \multirow{3}{*}{ Coxa $(\%)$} & Vegetal & 14,25 & 14,09 & 14,81 & 13,60 & $14,19 \mathrm{~b}$ & \multirow{3}{*}{ ns } & \multirow{3}{*}{0,0390} & \multirow{3}{*}{ ns } & \multirow{3}{*}{4,99} \\
\hline & Animal & 14,62 & 14,65 & 14,36 & 14,55 & $14,54 \mathrm{a}$ & & & & \\
\hline & Média & 14,44 & 14,37 & 14,58 & 14,07 & & & & & \\
\hline \multirow{3}{*}{ Sobrecoxa (\%) } & Vegetal & 15,18 & 15,87 & 15,41 & 15,41 & 15,47 & \multirow{3}{*}{ ns } & \multirow{3}{*}{ ns } & \multirow{3}{*}{ ns } & \multirow{3}{*}{5,39} \\
\hline & Animal & 15,39 & 15,86 & 15,64 & 15,70 & 15,65 & & & & \\
\hline & Média & 15,29 & 15,87 & 15,52 & 15,56 & & & & & \\
\hline \multirow{3}{*}{ Asa (\%) } & Vegetal & 10,37 & 10,30 & 10,50 & 10,70 & 10,47 & \multirow{3}{*}{ ns } & \multirow{3}{*}{ ns } & \multirow{3}{*}{ ns } & \multirow{3}{*}{5,33} \\
\hline & Animal & 10,78 & 10,74 & 10,74 & 10,32 & 10,65 & & & & \\
\hline & Média & 10,58 & 10,52 & 10,62 & 10,51 & & & & & \\
\hline \multirow{3}{*}{$\begin{array}{l}\text { Gordura } \\
\text { Abdominal (\%) }\end{array}$} & Vegetal & 1,87 & 1,62 & 1,30 & 1,30 & 1,52 & \multirow{3}{*}{$0,0001 * *$} & \multirow{3}{*}{ ns } & \multirow{3}{*}{ ns } & \multirow{3}{*}{21,41} \\
\hline & Animal & 1,75 & 1,44 & 1,46 & 1,28 & 1,48 & & & & \\
\hline & Média & 1,81 & 1,53 & 1,38 & 1,29 & & & & & \\
\hline
\end{tabular}

*Interação; **Efeito linear dos níveis de inulina ( $\left.\mathrm{GA}=1,75815-0,678651 \mathrm{X} ; \mathrm{R}^{2}=0,94\right)$; ${ }^{\text {ns }}$ - não significativo; $\mathrm{CV}$ - coeficiente de variação.

Fonte: Elaboração dos autores.

Os rendimentos de sobrecoxa e asa não foram influenciados $(\mathrm{P}<0,05)$ pelo do tipo de ração e os níveis de inulina não exerceram efeito $(\mathrm{P}>0,05)$ sobre as variáveis de rendimento de carcaça. De modo semelhante, Silva et al. (2011) não verificaram efeito dos diferentes promotores de crescimento sobre o rendimento de carcaça e cortes nobres na fase de um a 42 dias de idade.

Cancherini et al. (2005) trabalhando com duas fontes de proteína de origem animal (farinha de vísceras de aves e farinha de sangue bovino), não verificaram diferença significativa para rendimento de carcaça quanto à utilização ou não destes subprodutos de origem animal na ração de frangos de corte. Do mesmo modo, Godoi et al. (2008) não observaram efeito significativo $(\mathrm{P}>0,05)$ para utilização de prebióticos e probióticos no rendimento de carcaça e de peito. Resultados também relatados por Vargas Junior et al. (2002) e Pelicano et al. (2004), que também não encontraram efeito da utilização de prebióticos e probióticos sobre essas características. Entretanto, Albino et al. (2006) observaram melhora no rendimento de peito de frangos de corte alimentados com prebióticos e probióticos.

Resultados encontrados por Santos, Russo e Maiorka (2002), avaliando a utilização de seis fontes de aditivos promotores de crescimento para frangos de corte (antibiótico, MOS, FOS, ácido fumárico, extrato de cogumelo e probiótico), concluíram que a suplementação das dietas com aditivos influenciou positivamente no rendimento de carcaça, dos cortes nobres e na redução da gordura abdominal nos frangos de corte, quando comparados com a dieta controle, isenta de promotor de crescimento.

A inclusão de inulina reduziu linearmente a deposição de gordura abdominal $(\mathrm{P}<0,05)$ (Tabela 5), independente do tipo de ingrediente utilizado $(\mathrm{GA}=1,75815-0,678651 \mathrm{X} ; \mathrm{R} 2=0,94)$. Albino et al. (2006) relataram que a utilização de aditivos 
(prebióticos à base de mananoligossacarídeo e antibiótico avilamicina) em rações para frangos de cortes reduz a porcentagem de gordura abdominal.

Estudando a interação entre a inclusão de probiótico (Bacillus cereus e Bacillus subtilis), e rações com ingredientes de origem animal e vegetal Appelt et al. (2010) não encontraram efeito significativo sobre o rendimento de carcaça, cortes nobres e da gordura abdominal de frangos de corte abatidos aos 40 dias de idade. Entretanto, Faria Filho et al. (2002) e Cancherini et al. (2005) verificaram que a utilização de subprodutos de origem animal (farinha de carne e ossos e farrinha de vísceras) aumentou a porcentagem de gordura abdominal em frangos de corte.

Os resultados da análise econômica para utilização de inulina em rações com ingredientes de origem vegetal e animal, no período de 1 a 40 dias de idade, demonstram que a utilização de inulina elevou $(\mathrm{P}<0,05)$ o custo da ração (Tabela 6), independente do tipo de ingrediente utilizado.
Segundo Ramos et al. (2006) a análise econômica é um fator determinante na decisão pela utilização ou não de um ingrediente na alimentação das aves. Desta forma, de acordo com o índice de eficiência econômica (IEE) e o índice de custo (IC) foi observado que a inclusão de $0,25 \%$ de inulina na ração vegetal e $0 \%$ na ração animal proporcionou dietas mais econômicas, levando em consideração o custo da ração e o desempenho das aves.

De acordo com Ferreira e Kussakawa (1999), os probióticos podem não apresentar resultados positivos em relação ao ganho de peso e conversão alimentar das aves, pois ocorrem em função de diferentes fatores, como a sanidade das aves, o vazio sanitário e o nível de contaminação ambiental. Além disso, a eficácia do produto é estritamente dependente da quantidade e das características das cepas do microrganismo utilizado na elaboração do probiótico (TOURNUT, 1998), sendo difícil estabelecer um paralelo entre estudos e comparar resultados.

Tabela 6. Custo da ração (CR), índice de eficiência econômica (IEE) e índice de custo (IC) em função do tipo de ração e nível de inclusão de inulina em dietas para frangos de corte de 1 a 40 dias de idade.

\begin{tabular}{lcccc}
\hline \multirow{2}{*}{ Níveis de inulina (\%) } & $\mathrm{CR}(\mathrm{R} \$ / \mathrm{kg})^{\text {lin }}$ & $\mathrm{CR} / \mathrm{kg}$ PV ganho lin & IEE & IC \\
\cline { 2 - 5 } & \multicolumn{4}{c}{ Ração Vegetal } \\
\hline 0,00 & 2,48 & 3,94 & 99,13 & 100,88 \\
0,25 & 2,55 & 3,90 & 100,00 & 100,00 \\
0,50 & 2,63 & 4,26 & 91,55 & 109,23 \\
0,75 & 2,72 & 4,32 & 90,37 & 110,65 \\
\hline \multicolumn{5}{c}{ Ração Animal } \\
\hline 0,00 & $\mathrm{CR}(\mathrm{R} \$ / \mathrm{kg})^{\text {lin }}$ & $\mathrm{CR} / \mathrm{kg}$ PV ganho ${ }^{\text {lin }}$ & IEE \\
0,25 & 2,30 & 3,68 & 100,00 & 100,00 \\
0,50 & 2,38 & 3,78 & 97,33 & 102,74 \\
0,75 & 2,44 & 3,92 & 93,68 & 106,75 \\
\hline
\end{tabular}

${ }^{1} \mathrm{CR} / \mathrm{kg}$ PV ganho - Custo da ração pelo quilo de peso vivo ganho; ${ }^{\text {in }}$ - efeito linear dos níveis de inulina.

Fonte: Elaboração dos autores.

\section{Conclusões}

Conclui-se que pode ser utilizado até o nível de $0,75 \%$ de inulina em rações de origem animal ou vegetal, sem prejudicar o desempenho de frangos de corte no período de 1 a 40 dias de idade, reduzindo, inclusive, a percentagem de gordura abdominal. Além disso, o uso de ingredientes de origem animal nas rações de frangos de corte proporciona maior 
rendimento de carcaça e de coxa. A inclusão de inulina eleva o custo da ração, devendo ser utilizado com cautela, observando o custo benefício de seu uso.

\section{Referências}

ALBINO, L. F. T.; FERES, F. A.; DIONIZIO, M. A.; ROSTAGNO, H. S.; VARGAS JÚNIOR, J. G.; CARVAlHO, D. C. O.; GOMES, P. C.; COSTA, C. H. R. Uso de prebiótico à base de mananoligossacarídeo em rações para frangos de corte. Revista Brasileira de Zootecnia, Brasília, v. 35, n. 3, p. 742-749, 2006.

APPELT, M. D.; NUNES, R. V.; POZZA, P. C.; SILVA, W. T. M.; VENTURI, I.; NUNES, C. G. V. Níveis de probiótico em rações de origem animal e vegetal para frangos de corte. Revista Brasileira de Zootecnia, Brasília, v. 39, n. 4, p. 765-771, 2010.

BARBOSA, H. P.; FIALHO, E. T.; FERREIRA, A. S.; LIMA, G. J. M. M.; GOMES, M. F. M. Triguilho para suínos nas fases inicial de crescimento, crescimento e terminação. Revista Brasileira de Zootecnia, Brasília, v. 21, n. 5, p. 827-837, 1992.

BELlAVER, C.; FIALHO, E. T.; PROTAS, J. F. S.; GOMES, P. C. Radícula de malte na alimentação de suínos em crescimento e terminação. Pesquisa Agropecuária Brasileira, Brasília, v. 20, n. 8, p. 969-974, 1985.

BRUMANO, G.; GATTAS, G. Implicações sobre o uso de antimicrobianos em rações de monogástricos. Revista Eletrônica Nutritime, v. 6, n. 3, p. 953-959, 2009.

CANCHERINI, L. C.; JUNQUEIRA, O. M.; OLIVEIRA, M. C.; ANDREOTTI, M. O.; BARBOSA, M. J. B. Utilização de subprodutos de origem animal em dietas formuladas com base em proteína bruta e proteína ideal para frangos de corte de 22 a 42 dias de idade. Revista Brasileira de Zootecnia, Brasília, v. 34, n. 2, p. 535-540, 2005.

COLLINS, M. D.; GIBSON, G. R. Probiotics, prebiotics, and synbiotics: approaches for modulating the microbial ecology of the gut. The American Journal Clinical Nutrition, Bethesda, v. 69, n. 5, p. 1052S-1059S, 1999.

DIONIZIO, M. A.; BERTECHINI, A. G.; KATO, R. K.; TEIXEIRA, A. S. Prebióticos como promotores de crescimento para frangos de corte, desempenho e rendimento de carcaça. Ciência e Agrotecnologia, Lavras, p. 1580-1587, 2002. Edição Especial.

FARIA FILHO, D. E.; FARIA, D. E.; JUNQUEIRA, O. M.; RIZZO, M. F.; ARAÚJO, L. F.; ARAÚJO, C. S. S. Avaliação da farinha de carne e ossos na alimentação de frangos de corte. Revista Brasileira de Ciência Avícola,
Campinas, v. 4, n. 1, p. 1-9, 2002.

FERREIRA, F. A. B.; KUSSAKAWA, K. C. K. Uso de probióticos na alimentação de frangos de corte. Revista Biotecnologia Ciência \& Desenvolvimento, Brasília, ano II, n. 8, p. 40-43, 1999.

FLEMMING, J. S.; FREITAS, J. R. S.; FONTOURA, P.; MONTANHINI NETO, R.; ARRUDA, J. S. Use of mannanoligosaccharides in broiler feeding. Revista Brasileira de Ciência Avícola, Campinas, v. 6, n. 3, p. 159-161, 2004.

FUKATA, T.; SASAI, K.; MIYAMOTO, T.; BABA, E. Inhibitory effects of competitive exclusion and fructooligosaccharide, singly, and in combination, on Salmonella colonization of chicks. Journal of Food Protection, Des Moines, v. 62, n. 3, p. 229-233, 1999.

GIBSON, G. R.; ROBERFROID, M. B. Dietary modulation of the human colonic microbiota. Introducing the concept of prebiotics. Journal of Nutrition, Bethesda, v. 125, n. 6 , p. 1401-1412, 1995.

GODOI, M. J. S.; ALBINO, L .F. T.; ROSTAGNO, H. S.; GOMES, P. C.; BARRETO, S. L. T.; VARGAS JUNIOR, J. G. Utilização de aditivos em rações formuladas com milho normal e de baixa qualidade para frangos de corte. Revista Brasileira de Zootecnia, Brasília, v. 37, n. 6, p. 1005-1011, 2008.

HAULY, M. C. O.; MOSCATTO, J. A. Inulina e Oligofrutoses: uma revisão sobre propriedades funcionais, efeito prebiótico e importância na indústria de alimentos. Semina: Ciências Exatas e Tecnológica, Londrina, v. 23, n. 1, p. 105-118, 2002.

JUNQUEIRA, O. M.; TANAKA, A. H.; DALANEZI, J. A.; GARCIA, A. E.; DUARTE, K. F.; DALANEZI, L. M. Antibiótico, probiótico, prebiótico e simbiótico sobre o desempenho de frangos de corte de 1 a 21 dias de idade. Revista Brasileira de Ciência Avícola, Campinas, p. 60, 2006. Suplemento 8.

MAIA, R. C.; VIANA, M. T. S.; SILVA, E. A.; ALBINO, L. F.T .; LELES, J. P.; ROCHA JUNIOR, C. M. Efeito da suplementação de prebióticos sobre o desempenho de frangos de corte. In: ZOOTEC , 2009, Águas de Lindóia, SP. Anais... Águas de Lindóia, 2009. CD-ROM.

PALERMO, J. N. Uso de medicamentos veterinários: Impactos na moderna avicultura. In: SIMPÓSIO BRASIL SUL DE AVICULTURA, 2006, Chapecó. Anais... Concórdia: Embrapa Suínos e Aves, 2006. p. 70-78.

PELICANO, E. R. L.; SOUZA, P. A.; SOUZA, H. B. A.; OBA, A.; NORKUS, E. A.; KODAWARA, L. M.; LIMA, T. M. A. Performance of broilers fed diets containing natural growth promoters. Brazilian Journal of Poultry Science, Campinas, v. 6, n. 4, p. 231-236, 2004. 
RAMOS, L. S. N.; LOPES, J. B.; FIGUEIRÊDO, A. V.; FREITAS, A. C.; FARIAS, L. A.; SANTOS, L. S.; SILVA, H. O. Polpa de caju em rações para frangos de corte na fase final: desempenho e características de carcaça. Revista Brasileira de Zootecnia, Brasília, v. 35, n. 3, p. 804-810, 2006.

ROBERFROID, M. B. Inulin-type fructans: functional food ingredients. The Journal of Nutrition, Bethesda, v. 137, n. 11, p. 2493S-2502S, 2007. Suplemento.

ROSTAGNO, H. S.; ALBINO, L. F. T.; DONZELE, J. L.; GOMES, P. C.; OLIVEIRA, R. F.; LOPES, D. C.; FERREIRA, A. S.; BARRETO, S. L. T. Tabelas brasileiras para aves e suinos: composição de alimentos e exigências nutricionais. Viçosa: UFV, 2005. 186 p.

ROSTAGNO, H. S.; ALBINO, L. F. T.; TOLEDO, R. S.; CARVAlHO, D. C. O.; OLIVEIRA, J. E.; DIONIZIO, M. A. Avaliação de prebioticos à base de manonoligossacarídeos em rações de frangos de corte contendo milhos de diferente qualidade nutricional. Revista Brasileira de Ciência Avícola, Campinas, v. 5, p. 52, 2003.

UNIVERSIDADE FEDERAL DE VIÇOSA - UFV. SAEG. Sistema para análises estatísticas. Versão 8.0. Viçosa, MG: Fundação Arthur Bernardes, UFV, 1999.

SANTOS, E. C.; TEIXEIRA, A. S.; FREITAS, R. T. F.; RODRIGUES, P. B.; DIAS, E. S.; MURGAS, L. D. $\mathrm{S}$. Uso de aditivos promotores de crescimento sobre o desempenho, característica de carcaça e bactérias total do intestino de frango de corte. Ciência e Agrotecnologia, Lavras, v. 29, n. 1, p. 223-231, 2005.

SANTOS, S. A.; RUSSO, F. A.; MAIORKA, A. Uso de aditivos beneficiadores de crescimento sobre o rendimento de carcaça de frangos de corte. In: REUNIÃO ANUAL DA SOCIEDADE BRASILEIRA DE ZOOTECNIA, 39., 2002, Recife, PE. Anais... Recife, 2002. CD-ROM.

. Utilização de aditivos promotores de crescimento em substituição ao antibiótico avilamicina em dietas para frangos. In: REUNIÃO ANUAL DA SOCIEDADE BRASILEIRA DE ZOOTECNIA, 46., 2009, Maringá, PR. Anais... Maringá, 2009. CD-ROM.

SILVA, W. T. M.; NUNES, R. V.; POZZA, P. C.; POZZA, M. S. S.; APPELT, M. D.; EYNG, C. Avaliação de inulina e probiótico para frangos de corte. Acta Scientiarum. Animal Sciences, Maringá, v. 33, n. 1, p. 19-24, 2011.

STEFE, C. A.; ALVES, M. A. R.; RIBEIRO, R. L. Probióticos, prebióticos e simbióticos - artigo de revisão. Saúde \& Ambiente em Revista, Duque de Caxias, v. 3, n. 1, p. 16-33, 2008.

TOURNUT, J. R. Probiotics. In: REUNIÃO DA SOCIEDADE BRASILEIRA DE ZOOTECNIA, 35., 1998, Botucatu. Anais... Botucatu: SBZ, 1998, p. 179199.

VARGAS JUNIOR, J. G.; TOLEDO, R. S.;ALBINO, L. F. T.; ROSTAGNO, H. S.; OLIVEIRA, J. E.; CARVALHO, D. C. O. Características de carcaça de frango de corte, submetidos a rações contendo probióticos, prebióticos e antibióticos. In: REUNIÃO ANUAL DA SOCIEDADE BRASILEIRA DE ZOOTECNIA, 39., Recife. Anais... Recife, 2002. CD-ROM.

XU, Z. R.; HU, C. H.; XIA, M. S.; ZHAN, X. A.; WANG, M. Q. Effects of dietary fructooligosaccharide on digestive enzyme activities, intestinal microflora and morphology of male broilers. Poultry Science, Champaign, v. 82, n. 6, p. 1030-1036, 2003. 